\title{
NEW RECORDS OF CASCADE FROGS OF THE GENUS Odorrana (Amphibia: Anura: Ranidae) FROM VIETNAM
}

\section{Pham The Cuong ${ }^{1}$, Le Duc Minh ${ }^{2,3,4}$, Ngo Thi Hanh ${ }^{3,5}$, Nguyen Quang Truong ${ }^{1,6}$}

${ }^{1}$ Institute of Ecology and Biological Resources, VAST, Vietnam

${ }^{2}$ Faculty of Environmental Sciences, University of Science, Vietnam National University ${ }^{3}$ Central Institute for Natural Resources and Environmental Studies, Vietnam National University ${ }^{4}$ Department of Herpetology, American Museum of Natural History, Central Park West at $79^{\text {th }}$ Street, New York, New York 10024

${ }^{5}$ Faculty of Biology, University of Science, Vietnam National University

${ }^{6}$ Graduate University of Science and Technology, VAST, Vietnam

Received 5 July 2029, accepted 26 September 2020

\begin{abstract}
Odorrana fengkaiensis was recorded for the first time from Vietnam based on a new amphibian collection from Cao Bang, Bac Kan, Bac Giang, Quang Ninh provinces. Sequences of the specimens from Vietnam were identical to those of the paratypes of $O$. fengkaiensis from China. In addition, $O$. trankieni was newly recorded from Hoa Binh and Bac Giang provinces, Northern Vietnam, including the first description of female individuals. Genetic divergence between $O$. trankieni from Vietnam and its sister species, O. nasuta from China, ranged from 1.42 to $2.66 \%$. The intra-specific genetic distance within $O$. trankieni ranged from 0.68 to $1.88 \%$ between the northeastern and northwestern populations.
\end{abstract}

Keywords: Odorrana, morphology, molecular biology, new records, Vietnam.

Citation: Pham T. C., Le D. M., Ngo T. H., Nguyen Q. T., 2020. New records of cascade frogs of the genus Odorrana (Amphibia: Anura: Ranidae) from Vietnam. Academia Journal of Biology, 42(4): $33-40$. https://doi.org/10.15625/2615-9023/v42n4.15244

*Corresponding author email: nqt2@yahoo.com

C2020 Vietnam Academy of Science and Technology (VAST) 


\section{INTRODUCTION}

Cascade frogs of the genus Odorrana have a wide distribution in Asia, from Northeastern India and Southern China eastwards to Japan, throughout Indochina and southwards to Sumatra and Borneo (Frost, 2020). Odorrana belongs to one of the most diverse groups of amphibians with 59 recognized species and more than twenty new species have been described in the last ten years (Frost, 2020). Due to morphologically similarity in the genus, species that were formally thought to be widespread are now being recognized as complexes of species with much narrower distributions (Wang et al., 2015). In Vietnam, Pham et al. (2016a, b) recently discovered a new species (Odorrana mutschmanni Pham, Nguyen, Le, Bonkowski \& Ziegler, 2016) and a new country record $(O$. lipuensis Mo, Chen, Wu, Zhang \& Zhou, 2015).

Based on newly collected specimens of amphibians from northern Vietnam, we herein record Odorrana fengkaiensis for the first time from Vietnam. In addition, we report new provincial records of $O$. trankieni from Hoa Binh and Bac Giang provinces, including the first description of female individuals.

\section{MATRIAL AND METHODS}

Field surveys were conducted in Tay Yen $\mathrm{Tu}$ Nature Reserve, Bac Giang Province in April 2008 and in October 2009; in Ha Lang District, Cao Bang Province in April 2012; in Thuong Tien Nature Reserve, Hoa Binh Province in October 2010; in Phu Yen District, Son La Province in October 2011; in Kim Hy Nature Reserve, Bac Kan Province in April 2014; in Hai Ha District, Quang Ninh Province in May 2016 (Fig. 1). Specimens were collected between 19:00 and 24:00 h. After photographing in life, specimens were euthanized in a closed vessel with a piece of cotton wool containing ethyl acetate (Simmons, 2002), fixed in $80 \%$ ethanol for five hours, and then transferred to $70 \%$ ethanol for permanent storage. Tissue samples were preserved separately in $70 \%$ ethanol prior to fixation. Specimens referred to in this paper are deposited in the collections of the
Institute of Ecology and Biological Resources (IEBR) and the Vietnam National Museum of Nature (VNMN), Ha Noi, Vietnam.

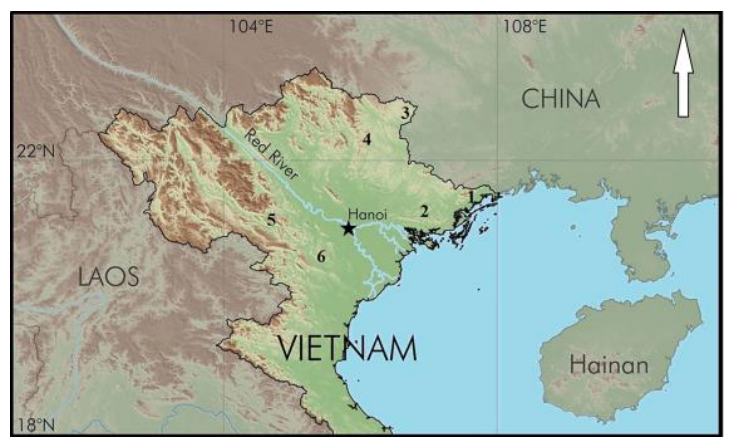

Figure 1. Map showing the sampling sites in Northern Vietnam: (1) Hai Ha District in Quang Ninh Province, (2) Tay Yen Tu Nature Reserve in Bac Giang Province, (3) Ha Lang District in Cao Bang Province, (4) Kim Hy Nature

Reserve in Bac Kan Province, (5) Phu Yen District in Son La Province, and (6) Thuong Tien Nature Reserve in Hoa Binh Province

Morphological characters. Measurements were taken with a digital caliper to the nearest $0.1 \mathrm{~mm}$. Abbreviations are as follows: SVL: snout-vent length, HL: head length (from the back of mandible to tip of snout), HW: maximum head width (across angle of jaws), RL: rostral length (from anterior corner of orbit to tip of snout), ED: eye diameter, UEW: maximum width of upper eyelid, IND: internarial distance, IOD: interorbital distance, DAE: distance between anterior corners of eyes, DPE: distance between posterior corners of eyes, NS: distance from nostril to the tip of snout, EN: distance from anterior corner of eye to the nostril, TD: tympanum diameter, TYE: distance from anterior margin of tympanum to posterior corner of the eye, UAL: upper arm length (from axilla to elbow), FAL: fore arm length (from elbow to tip of third finger), TFL: third finger length, fd3: width of disc of finger III, IPT: inner palmar tubercle length, OPT: outer palmar tubercle length, NPL: nuptial pad lengthfinger I, FeL: femur length (from vent to knee), TbL: tibia length (from knee to tarsus), TbW: tibia width, FoL: foot length (from 
tarsus to the tip of fourth toe), FTL: fourth toe length, IMT: inner metatarsal tubercle length, td4: width of disc of toe IV. For webbing formula we followed Glaw \& Vences (2007).

Molecular analysis. The tissue samples of Odorrana were extracted using Dneasy Blood and Tissue kits (Qiagen, Germany) following protocols by the manufacturer. Extracted DNA was then amplified by HotStar Taq Mastermix (Qiagen, Germany). The standard PCR conditions were $95{ }^{\circ} \mathrm{C}$ for $15 \mathrm{~min}$ to active Taq, 35 cycles at $95{ }^{\circ} \mathrm{C}$ for $30 \mathrm{~s}, 50{ }^{\circ} \mathrm{C}$ for $45 \mathrm{~s}, 72{ }^{\circ} \mathrm{C}$ for $1 \mathrm{~min}$, a final elongation at $72{ }^{\circ} \mathrm{C}$ for $10 \mathrm{~min}$. The PCR components were $2 \mu \mathrm{l}$ of each primer at $10 \mu \mathrm{mol} / \mu \mathrm{l}, 5 \mu \mathrm{l}$ water, $10 \mu 1$ of Mastermix and $2 \mu 1$ DNA template. The primers used to amplify a fragment of the mitochondrial DNA 16S gene using a pair of primers AR (5'-CGCCTGTTTATCAAAAA CAT-3') and BR (5'-CCGGTCTGAACTC AGATCACGT-3') (Palumbi et al., 1991). PCR products were visualized using electrophoresis through a $1 \%$ agarose gel, marker $1 \mathrm{~kb}, 1 \mathrm{X}$ TBE and stained with ethidium bromide and photographed under UV light. Successful amplifications were purified using GeneJet PCR Purification Kit (ThermoFisher Scientific, Lithuania). Cleaned PCR products were sent to $1^{\text {st }}$ Base (Malaysia) for sequencing in both directions. Sequences were validated with Sequencher v4.10 (Gene Codes, Ann Arbor, MI) with default setting and analyzed using BLAST Tool as implemented in the National Center for Biotechnology Information (NCBI, https://blast.ncbi.nlm.nih.gov/). The sequences were uploaded on Genbank under accession numbers KX893887-KX893890, KX893900, KX893909.

\section{RESULTS}

Odorrana fengkaiensis Wang, Lau, Yang, Chen, Liu, Pang \& Liu, 2015

\section{Fengkai Cascade Frog (Fig. 2)}

Specimens examined $(\mathrm{n}=8)$. One adult female (IEBR 3654) collected by T. Q. Nguyen \& C. T. Pham on 8 April 2008, in the evergreen forest near Dong Ri Station $\left(21^{\circ} 09.851^{\prime} \mathrm{N}, 106^{\circ} 49.301^{\prime} \mathrm{E}\right.$, at an elevation of $361 \mathrm{~m}$ ) and two adult females (IEBR A.2013.73, IEBR 4751) collected by C. T. Pham, T. T. Nguyen \& T. Ziegler in October 2009 , in the evergreen forest near Dong Thong Station $\left(21^{\circ} 10.862^{\prime} \mathrm{N}, 106^{\circ} 43.671^{\prime} \mathrm{E}\right.$, at an elevation of $168 \mathrm{~m}$ ), Tay Yen Tu Nature Reserve, Bac Giang Province; three adult females (IEBR A.2015.82, A.2015.83, IEBR 3886) collectes by T. Q. Nguyen et al. On 10 April 2012 in the karst forest near Lung Tung Village $\left(22^{\circ} 43.795^{\prime} \mathrm{N}, 106^{\circ} 35.392^{\prime} \mathrm{E}\right.$, at an elevation of $669 \mathrm{~m}$ ), Kim Loan Commune, Ha Lang District, Cao Bang Province; one adult female (IEBR 4752) collected by D. T. Pham in April $2014 \quad\left(22^{\circ} 13.210^{\prime} \mathrm{N}\right.$, $106^{\circ} 03.092^{\prime} \mathrm{E}$, at an elevation of $393 \mathrm{~m}$ ), Kim Hy Nature Reserve, Bac Kan Province; and one female (IEBR 4753) collected by C. T. Pham and T. V. Nguyen on 8 May 2016 in the evergreen forest near Tai Chi Village $\left(21^{\circ} 30.677^{\prime} \mathrm{N}, 107^{\circ} 40.383^{\prime} \mathrm{E}\right.$, at an elevation of $73 \mathrm{~m}$ ), Quan Son Commune, Hai $\mathrm{Ha}$ District, Quang Ninh Province.

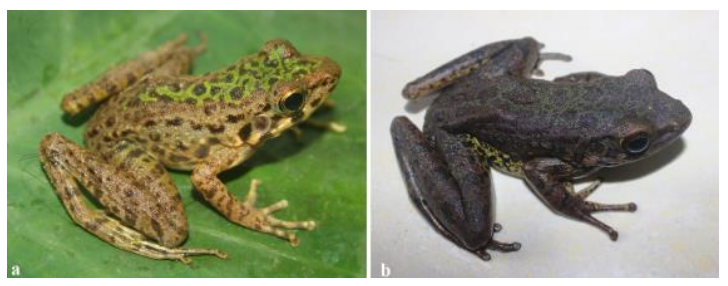

Figure 2. Odorrana fengkaiensis: a) IEBR 4751 from Bac Giang Province, b) IEBR 4753 from Quang Ninh Province

Description. Morphological characters of specimens from Bac Giang, Cao Bang, Bac Kan and Quang Ninh provinces agreed well with the description of Wang et al. (2015). Size lage (SVL 96.5-105.5 mm, TB \pm SD $100.9 \pm 2,8 \mathrm{~mm}, \mathrm{n}=8$ in females); head longer than wide (HL/HW 1.07-1.14); snout rounded in dorsal view, projecting beyond lower jaw; nostril lateral, closer to tip of snout than to eye (NS 6.2-7.6 mm, EN 7.8-8.8 $\mathrm{mm}$ ); canthus distinct; pupil horizontally oval; loreal region slightly concave and oblique; snout length greater than eye diameter (RL/ED 1.14-1.53); internarial distance wider 
than interorbital distance and upper eyelid (IND 9.7-11.9 mm, IOD 8.1-11.3 mm, UEW 6.4-7.7 $\mathrm{mm}$ ); tympanum distinct, rounded smaller than eye diameter (TD/ED 0.43$0.54)$; vomerine teeth present, in two oblique ridges; tongue cordiform, deeply notched posteriorly; females contained creamy yellow eggs with black poles.

Forelimbs robust (UAL 15.7-19.0 mm); shorter than the length of hand (FAL 47.3$50.4 \mathrm{~mm}$ ); tips of fingers expanded with circummarginal grooves, width of finger III disc greater than two times of the width of phalange; relative finger lengths II $<$ I $<$ IV $<\mathrm{III}$; fingers free of webbing; subarticular tubercles round, formula $1,1,2,2$; inner metatarsal tubercle oval, elongate; outer metatarsal tubercle small.

Hindlimbs robust, long, thigh shorter than tibia (FeL 47.0-53.4 mm, TbL 56.6-63.9 $\mathrm{mm}$ ); tibia approximately four to five times longer than wide (TbL/TbW 3.9-4.9); tips of toes expanded with circummarginal grooves; width of toe IV disc smaller than two times of the width of phalange, smaller than width of finger III disc; relative toe lengths I < II < III $<\mathrm{V}<\mathrm{IV}$; webbing well developed, to posterior of terminal phalanx; subarticular tubercles present, formula $1,1,2,3,2$; inner metatarsal tubercle elongate; outer metatarsal tubercle absent; tibio-tarsal articulation reaching beyond the tip of snout.

Skin. Dorsal surface of head and body smooth; flanks with tubercles; tiny spinules on upper edge of eyelid, anterior and posterior edge of tympanum; supratympanic fold weakly developed; dorsolateral fold absent; dorsal surface of limbs smooth; throat, chest, belly and ventral surface of thigh smooth.

Coloration in life. Iris black, surrounded by golden network; head and anterior of dorsum green with brown mottling; posterior of dorsum and flanks brown, with some large black spots; dorsal surface of fore and hindlimbs brown with black cross bands; upper lip with black bars; throat, chest cream with dark brown mottling; belly immaculate white.
Ecological notes. The specimens were found between 19:00 and 23:00 on the rocks or on the ground in rocky streams. The surrounding habitat was a mixed secondary evergreen forest or karst forest of medium and small hardwoods and shrubs.

Distribution. The species was previously known only from Guangdong and Guangxi provinces, China (Wang et al., 2015; Frost, 2020). The new records of this species in northern Vietnam are approximately 440 to $570 \mathrm{~km}$ distant from the holotype locality and are approximately $60 \mathrm{~km}$ to $100 \mathrm{~km}$ distant from the paratypes locality in China.

Remarks. Odorrana fengkaiensis morphologically is similar to $O$. hainanensis Fei, Ye \& Li, 2001 but it differs from the latter by relative finger lengths II $<$ I $<$ IV $<$ III (vs. II < IV $<$ I < III in O. hainanensis), tibio-tarsal articulation reaching beyond the tip of snout (vs. reaching between anterior corner of the eye and tip of snout in in $O$. hainanensis), and females containing eggs with black mature oocytes (vs. creamy yellow eggs with black poles in $O$. hainanensis).

Three sequences of $585 \mathrm{bps}$ from Vietnam with voucher numbers IEBR 3942, VFU KH 073, IEBR A.2015.83 (Genbank accession number KX893887, KX893888, KX893909) were successfully obtained. Our BLAST search showed that they are identical to those of the paratypes of $O$. fengkaiensis (Genbank accession number KT315375, KT315376, KT315377, KT315378, KT315379, KT315380, KT315381) collected in Heishiding Natural Reserve, Fengkai County, Guangdong Province, China (Wang et al., 2015). The new records of $O$. fengkaiensis from Bac Giang Province, Vietnam were approximately $1.37-2.44 \%$ divergent from the sequences of $O$. hainanensis (Genbank accession number KF185032, KT315383, KT315384, KU840592, KX056491) collected in Wuzhishan Mountain, Wuzhishan and Diaoluoshan Forest Park, Lingshui Country, Hainan Province, China (Chen et al., 2018; Goutte et al., 2016; Huang et al., 2017; Wang et al., 2015); and $3.48 \%$ from the paratype of $O$. bacboensis (Genbank accession number 
DQ650569) collected in $\mathrm{Pu}$ Mat National Park, Con Cuong District, Nghe An Province, Vietnam (Stuart et al., 2007).

\section{Odorrana trankieni (Orlov, Le \& Ho 2003)}

\section{Trankien Frog (Fig. 3)}

Specimens examined $(\mathrm{n}=12)$. Two adult males (IEBR A. 2015.69, IEBR 2015.71) and two adult females (IEBR A.2015.68, IEBR A.2015.70) collected by C. T. Pham in October 2010, in evergreen forest $\left(20^{\circ} 38.100^{\prime} \mathrm{N}, 105^{\circ} 26.230^{\prime} \mathrm{E}\right.$, at an elevation of $450 \mathrm{~m}$ ), Thuong Tien Nature Reserve, Hoa Binh Province; on adult male (IEBR A. 2013.74) collected by C. T. Pham, T. T. Nguyen \& T. Ziegler in October 2009, in the evergreen forest near Dong Ri Station $\left(21^{\circ} 09.662^{\prime} \mathrm{N}, 106^{\circ} 49.236^{\prime} \mathrm{E}\right.$, at an elevation of 400 m), Tay Yen Tu Nature Reserve, Bac Giang Province; four adult males (VNMN 04030, 04035, 04061, 04062, 04063) and three adult females (VNMN 04031, 04032, 04060) collected by H. T. An and C. V. Hoang on 20 October 2011, in evergreen forest $\left(21^{\circ} 11.330^{\prime} \mathrm{N}, 104^{\circ} 45.300^{\prime} \mathrm{E}\right.$, at an elevation of $851 \mathrm{~m}$ ), Muong Do Commune, Phu Yen District, Son La Province.

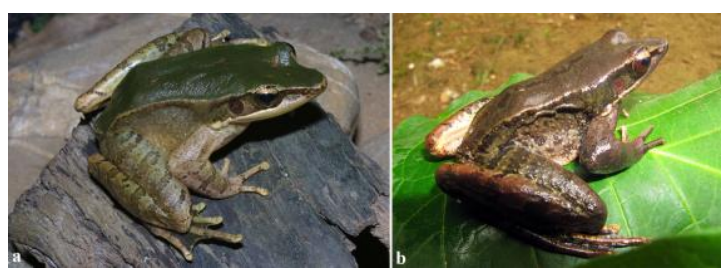

Figure 3. Odorrana trankieni: a) IEBR A.2015.69 from Hoa Binh Province, b) IEBR A. 2013.74 from Bac Giang Province

Description. Morphological characters of the specimens from Hoa Binh, Son La and Bac Giang Provinces agreed well with the original description of Orlov et al. (2003). We herein provide an extended description of $O$. trankieni based on 7 males and 5 females. Size large, males smaller than females (SVL $75.2-84.1 \mathrm{~mm}, \mathrm{~TB} \pm \mathrm{SD} 78.4 \pm 2.9 \mathrm{~mm}, \mathrm{n}=7$ in males, SVL $86.2-95.8 \mathrm{~mm}$, TB \pm SD 90.8 $\pm 3.6 \mathrm{~mm}, \mathrm{n}=5$ in females); head longer than wide (HL/HW 1.26-1.36 in males, HL/HW
$1.22-1.30$ in females); snout pointed in dorsal view, projecting beyond lower jaw; nostril lateral, closer to eye than to tip of snout (NS 5,7-6.9 $\mathrm{mm}$, EN 4.8-5.6 $\mathrm{mm}$ in males; NS 6.6-7.4 mm, EN $6.2-6.7 \mathrm{~mm}$ in females); canthus distinct; pupil horizontally oval; loreal region slightly concave and oblique; snout length greater than eye diameter (RL/ED 1.16-1.33 in males, RL/ED 1.131.37 in females); internarial distance wider than interorbital distance and upper eyelid (IND 7.9-9.5 mm, IOD 6.2-7.0 mm, UEW 5.5-6.6 mm in males; IND 9.3-10.4 mm, IOD 7.4-8.9 mm, UEW 6.3-7.5 $\mathrm{mm}$ in females); tympanum distinct, round smaller than eye diameter (TD/ED 0.44-0.53 in males, 0.440.49 in females); vomerine teeth present, in two oblique ridges; tongue cordiform, deeply notched posteriorly; males with vocal sacs; females containing creamy yellow eggs without black poles.

Forelimbs robust (UAL $12.3-14.5 \mathrm{~mm}$ in males, UAL 13.7-17.4 $\mathrm{mm}$ in females); shorter than the length of hand (HAL 33.7$39.3 \mathrm{~mm}$ in males, FAL $38.7-42.2 \mathrm{~mm}$ females); tips of fingers slightly expanded with circummarginal grooves, width of finger III disc smaller than two times of the width of phalange; relative finger lengths II $<$ IV $<$ I $<$ III; subarticular tubercles round, formula 1,1 , $2,2(1,2,3,2)$; inner metatarsal tubercle oval, elongate; outer metatarsal tubercle small; nuptial pads present on Fig. 1.

Hindlimbs robust, long, thigh shorter than tibia (FeL 29.2-42.0 mm, TbL 42.0-49.5 mm in males; FeL $38.3-47.8 \mathrm{~mm}$, TbL 49.7-57.8 $\mathrm{mm}$ in females); tibia approximately four to five times longer than wide (TbL/TbW 4.1-5.1 in males, TbL/TbW 4.1-4.7 in females); tips of toes slightly expanded with circummarginal grooves; width of toe IV disc smaller than two times of the width of phalange, smaller than width of finger III disc; relative toe lengths I < II $<$ III $<$ V < IV; webbing well developed, to posterior of terminal phalanx; subarticular tubercles present, formula 1, 1, 2, 3, 2; inner metatarsal tubercle elongate; outer metatarsal tubercle absent; tibio-tarsal articulation reaching to the eye. 
Skin. Dorsal surface of head and body smooth; tiny spinules on flanks, upper edge of eyelid, anterior and posterior edge of tympanum; supratympanic fold present; dorsolateral fold well developed; throat, chest, belly and ventral surface of thigh smooth.

Coloration in life. Iris black, surrounded by red golden network; dorsum olive brown or dark green with some red brown spots; flanks brown with or without dark spots; dorsal surface of fore and hindlimbs brown with dark brown cross bands; upper lip brown or white; throat, chest cream with dark brown mottling; belly immaculate white or cream with dark brown mottling.

Sexual dimorphism. Males are smaller than females (SVL 75.2-84.1 mm, $\mathrm{n}=7$ vs. SVL 86.2-95.8 $\mathrm{mm} \mathrm{mm,} \mathrm{n}=5$, respectively). Males have strong arms, finger I with white nuptial pad, and a pair of gular pouches below jaw articulations. Gravid females containing creamy yellow eggs without black poles.

Ecological notes. The specimens were found between 19:00 and 22:00 on the rocks, in the rocky streams. The surrounding habitat was mixed secondary evergreen forest of medium and small hardwoods with bamboo, shrubs and arrowroot.

Distribution: This species is currently known only from the type locality in Son La Province, northern Vietnam (Frost, 2020). This is the first record of $O$. trankieni from Hoa Binh and Bac Giang provinces.

Revised diagnosis. (1) SVL 75.2-84.1 mm in males, SVL 86.2-95.8 mm in females; (2) head longer than wide, snout strongly narrowed, thin, protruding; (3) vomerine teeth present; (4) tympanum distinct, approximately $50 \%$ of eye diameter; (5) dorsum smooth, flanks with small tubercles; (6) upper edge of eyelid, anterior and posterior edge of tympanum with white tiny spinules; (7) supratympanic fold present; (8) dorsolateral fold well developed; (9) toes fully webbed to posterior of terminal phalanx; (10) males with nuptial pad on finger I and a pair of gular pouches; (11) females containing creamy yellow eggs without black poles; (12) dorsum olive brown or dark green with some red brown spots.

Remarks. O. trankieni is morphologically similar to $O$. nasuta by having moderate lateral folds in males; saw-tooth like spinules on the lower jaw; vocal sac external; very long and strongly protruding snout. But it differs from $O$. nasuta by having a larger size (SVL 75.2-84.1 $\mathrm{mm}$ in males and 86.8-95.9 $\mathrm{mm}$ in females vs. $57.1-63.2 \mathrm{~mm}$ in males and 73.1-74.6 $\mathrm{mm}$ in females in $O$. nasuta) (Orlov et al., 2003; Fei et al., 2009; Fei et al., 2010, this study).

Three sequences of $585 \mathrm{bp}$ from Vietnam with voucher numbers IEBR A.2013.74, VNMN 04035, IEBR A.2015.69 (Genbank accession number KX893890, KX893900, KX893889) were successfully obtained. Our BLAST search showed that the genetic distance between the sequences of $O$. trankieni from Vietnam and that of the specimen of $O$. nasuta collected in Wuzhishan, Hainan Province, China (Genbank accession number KF185053, 16S gene) was approximately $1.42-2.66 \%$. The intra-specific genetic distance between the sequences of $O$. trankieni was from 0.68 $1.88 \%$.

\section{DISCUSSION}

Our findings bring the total species number of the genus Odorrana to 24 in Vietnam, namely Odorrana absita (Stuart \& Chan-ard); $O$. andersonii (Boulenger); O. bacboensis (Bain, Lathrop, Murphy, Orlov \& Ho); $O$. banaorum (Bain, Lathrop, Murphy, Orlov \& Ho); O. chapaensis (Bourret); O. chloronota (Günther); O. fengkaiensis Wang, Lau, Yang, Chen, Liu, Pang \& Liu; O. geminata Bain, Stuart, Nguyen, Che \& Rao; O. gigatympana Orlov, Ananjeva \& Ho; O. grahami (Boulenger); O. graminea (Boulenger); $O$. jingdongensis Fei, Ye \& Li; O. junlianensis Huang, Fei \& Ye; O. khalam (Stuart, Orlov \& Chan-ard); O. lipuensis Mo, Chen, Wu, Zhang \& Zhou; O. margaretae (Liu); O. morafkai (Bain, Lathrop, Murphy, Orlov \& Ho); $O$. mutschmanni Pham, Nguyen, Le, Bonkowski \& Ziegler; O. nasica (Boulenger); O. orba 
(Stuart \& Bain); O. schmackeri (Boettger); O. tiannanensis (Yang \& Li); O. trankieni (Orlov, Le \& Ho); O. yentuensis Tran, Orlov \& Nguyen (Nguyen et al., 2009; Pham et al., 2016a, 2016b; Frost, 2020).

Odorrana trankieni is morphologically similar to $O$. exiliversabilis, $O$. nasica, $O$. nasuta, $O$. versabilis, $O$. yentuensis, but it differs from $O$. exiliversabilis, $O$. nasica, $O$. yentuensis by having a larger size (SVL 75.2$84.1 \mathrm{~mm}$ in males, $86.2-95.8 \mathrm{~mm}$ in females vs. $42-45 \mathrm{~mm}$ in males, $52-62 \mathrm{~mm}$ in females in $O$. exiliversabilis; 41-49 in males, 67-77 in females in $O$. nasica; $44-46 \mathrm{~mm}$ in males, 59-62 $\mathrm{mm}$ in females in $O$. yentuensis); from $O$. versabilis by having external subgular (vs. internal subgular in $O$. versabilis), and a higher ratio of $\mathrm{HL} / \mathrm{HW}$ (1.22-1.36 vs. 1.08 in $O$. versabilis); from $O$. nasuta by having a larger size (SVL 75.2$84.1 \mathrm{~mm}$ in males and $86.8-95.9 \mathrm{~mm}$ in females vs. $57.1-63.2 \mathrm{~mm}$ in males 73.1-74.6 $\mathrm{mm}$ in females in $O$. nasuta) (Bain et al., 2003; Orlov et al., 2003; Tran et al., 2008; Fei et al., 2009; Fei et al., 2012; this study).

Genetically, Odorrana fengkaiensis samples from Vietnam are identical to those from China, suggesting that the species is widely distributed across southeastern Asia. The species is placed in the same clade as $O$. hainanensis and $O$. bacboensis and recovered as a sister species to the former species (Subgroup 4 of Group D) in Ngo et al. (2016). Pairwise genetic divergence between species of the group is between $1.37-3.48 \%$. On the other hand, $O$. trankieni and $O$. nasuta are shown to be sister taxa in the Subgroup 3 of Group D (Ngo et al., 2016). The two species have pairwise genetic distance of 1.42-2.66\%. The observed molecular variation within $O$. trankieni ranging from $0.68 \%$ to $1.88 \%$ is quite substantial, considering the distance between the two closely related species, and warrants further investigation of the different geographic populations in Vietnam.

Acknowledgements: We are grateful to the directorates of the Forest Protection Departments of Bac Giang, Bac Kan, Cao
Bang, Quang Ninh, Hoa Binh, Son La, Thanh Hoa, Nghe An provinces for support of our field work and issuing relevant permits. We thank H. T. An, C. V. Hoang, D. T. K. Pham, T. T. Nguyen (Hanoi), T. V. Nguyen (Ninh Binh), S. Herbst, T. Lehmann (Cologne) for their assistance in the field. Many thanks T. Ziegler (Cologne Zoo) for his support of our research work in Vietnam, D. T. A. Tran for her comments on our manuscript. We thank E. Sterling (New York) and K. Koy (Berkeley) for providing the map. This research was supported by the National Foundation for Science and Technology Development (NAFOSTED, Grant No. 106.05-2017.329).

\section{REFERENCES}

Chen X., Chen Z., Jiang J., Qiao L., Lu Y., Zhou K., Zheng G., Zhai X., Liu J., 2013. Molecular phylogeny and diversification of genus Odorrana (Amphibia, Anura, Ranidae) inferred from two mitochondrial genes. Molecular Phylogenetics and Evolution, 69: 1196-1202.

Fei L., Hu S., Ye C., Huang Y., 2009. Fauna Sinica. Amphibia. Volume 3. Anura. Science Press, Beijing, China, 887 pp.

Fei L., Ye C, Jiang J., 2012. Colored atlas of Chinese amphibians and their distributions. Sichuan, China: Sichuan Publishing House of Science \& Technology, China, 519 pp.

Fei L., Ye C., Li C., 2001. Descriptions of two new species of the genus Odorrana in China. Acta Zootaxonomica Sinica/Dong wu fen lei xue bao, 26: 108-114.

Frost D.R., 2020. Amphibian Species of the World: an on-line reference. Version 6.0. American Museum of Natural History, New York, USA. Available from http:// https://amphibiansoftheworld.amnh.org/ (accessed on 10 April 2020).

Glaw F., Vences M., 2007. A field guide to the amphibians and reptiles of Madagascar. Third Edition, Frosch Verlag, Cologne, 496 pp.

Li S., Xu N., Jiang J., Wei G., Wang B., 2018. A new species of the odorous frog genus 
Odorrana (Amphibia, Anura, Ranidae) from southwestern China. PeerJ, 6(e5695): 1-28.

Matsui M., 1994. A taxonomic study of the Rana narina complex, with description of three new species (Amphibia: Ranidae). Zoological Journal of the Linnean Society, 111: 385-415.

Mo Y., Chen W., Wu H., Zhang W., Zhou S., 2015. A new species of Odorrana inhabiting complete sarkness in a karst cave in Guangxi, China. Asian Herpetological Research, 6: 11-17.

Ngo A., Murphy R. W., Liu W., Lathrop A., Orlov N. L., 2006. The phylogenetic relationships of the Chinese and Vietnamese Waterfall frogs of the genus Amolops. Amphibia-reptilia, 27: 81-92.

Ngo H. T., Le M. D., Pham C. T., Nguyen T. Q., 2016. Species diversity and genetic relationships of genus Odorrana (Amphibia: Aruna: Ranidae) from northern Vietnam. Proceedings of the Third Vietnamese National Symposium on Reptiles and Amphibians. Publishing House for Science and Technology, Hanoi, pp. 137-145.

Nguyen S. V., Ho C. T., Nguyen T.Q., 2009. Herpetofauna of Viet Nam. Edition Chimaira, Frankfurt am Main, Germany, $768 \mathrm{pp}$.

Orlov N. L., Le N. N., Ho T. C., 2003. A new species of Cascade Frog from North Vietnam (Ranidae, Anura). Russian Journal of Herpetology, 10: 123-134.
Palumbi S. R., Martin A. P., Romano S., McMillan W. O., Stice L., Grabowski G., 1991. The Simple Fools Guide to PCR. A collection of PCR protocols, version 2 . Honolulu: University of Hawaii.

Pham C. T., Nguyen T. Q., Bernardes M., Nguyen T. T., Ziegler T., 2016. First records of Bufo gargarizans Cantor, 1842 and Odorrana lipuensis Mo, Chen, Wu, Zhang et Zhou, 2015 (Anura: Bufonidae) from Vietnam. Russian Journal of Herpetology, 23: 103-107.

Pham C. T., Nguyen T. Q., Le M. D., Bonkowski M., Ziegler T., 2016. A new species of Odorrana (Amphibia: Anura: Ranidae) from Vietnam. Zootaxa, 4084: 421-435.

Simon C., Frati F., Beckenbach A., Crespi B., Liu H., Flook P., 1994. Evolution, weighting, and phylogenetic utility of mitochondrial gene sequences and a compilation of conserved polymerase chain reaction primers. Annals of the Entomological Society of America, 87: 651-701.

Stuart B. L., Bain R. H., 2005. Three new species of spinule-bearing frogs allied to Rana megatympanum Bain, Lathrop, Murphy, Orlov \& Ho, 2003, from Laos and Vietnam. Herpetologica, 61: 478-492.

Wang Y. Y., Lau M. N., Yang J. H., Chen G. L., Liu Z. Y., Pang H., Liu Y., 2015. A new species of the genus Odorrana (Amphibia: Ranidae) and the first record of Odorrana bacboensis from China. Zootaxa, 3999: 235-254. 